\section{ESF works, don't change it}

SIR - The European Science Foundation (ESF), based in Strasbourg, is a nongovernmental collaboration between the major national research funding organizatins in Europe. ESF has 55 member organizations from 20 European countries, a staff of 29 and an overall budget for 1994 of FFr73.5 million. Of this budget, FFr37.9 million goes directly to promoting research, in the form of programmes and networks. Part of the rest is spent on developing new proposals.

We became in 1992 the co-chairmen of the programme REHE (Relativistic Effects in Heavy-Element Chemistry and Physics, planned for 1993-97), grouping 12 countries and having a yearly budget of about FFr 0.8 million. This sum buys $2-5$ workshops a year, contributes to a Euroconference every second year and made possible 26 short-term visits in 1993. Most of these visits led to one or more publications that otherwise would not exist. That output/input ratio seems to us extremely efficient.

The allocations are made by a steering group or, empowered by them, the cochairman. Most correspondence is by email or fax. If necessary, a decision can be made in a day and the money actually paid out by Strasbourg in 2-3 weeks.

We know of few other organizations on this medium-sized scale and with this efficiency and speed. Obviously one requires a subject that still has unsaturated collaboration potential, and personal chemistry that works.

We have recently learned that the activities of ESF are being discussed, the issue being an eventual larger role in science policy matters. It is not within our competence to say whether this is desirable, but we would definitely regard it unwise to do so at the cost of ESF's concrete scientific activity.

\section{Pekka Pyykkö}

Department of Chemistry,

University of Helsinki,

POBox 19 (Et. Hesperiankatu 4),

FIN-00014 Helsinki, Finland

\section{Bernd Hess}

Department of Physical and Theoretical

Chemistry,

University of Bonn,

D-53115 Bonn, Germany

\section{No need to scoff}

SIR - As a foreigner who has spent three and a half years working at a British university, I feel reasonably acquainted with British idiosyncrasies. Yet I was taken aback by the vehemence of your reaction to the plans for an expatriate university in Thailand, and especially by the references to culture (Nature 371, 462; 1994). The article, it occurs to me, would be more fitting in an issue of Nature of a hundred years ago. Culture is being exported in many forms all across the world, not least by "international journals". If the plan is properly managed, the possibilities offered by a university could compensate for many such exports of lesser value. The fact that the United States has universities abroad should not automatically cause traditionalist British scientists to scoff at the idea.

\section{Werner Sieber}

rue du Botzet 3 ,

1700 Fribourg,

Switzerland

SIR - The export of British universities to faraway lands is not a new phenomenon-many former British colonies have wellestablished universities that began as offshoots of British universities. Most have survived and adapted, with a gradual replacement of expatriate staff by wellqualified local academics. Research does pose a dilemma, because in a new university there is a temptation to emulate illustrious (and expensive) facilities overseas only to find that the reality of shortterm expatriate appointments prevents useful research from being completed. But robust and useful research is possible, particularly when it takes into account the context in which the new university is set - a new set of research possibilities will be perceived by open minds. So perhaps the founding of a new university in Thailand is not a time for cynicism, but an opportunity to nurture a valuable new resource.

\section{Richard Dryden}

Tor \& South West College of Health,

Kinninmont Centre,

West of England Eye Infirmary,

Magdalen Street,

ExeterEX2 4HT, UK

\section{Divergent proteins and views}

SIR - Alexander Rich ${ }^{1}$ says that Linus Pauling, together with Emile Zuckerkandl, in 1962, "by looking at changes in the amino-acid sequence of haemoglobin in different animals, could correlate the changes with the evolutionary period at which the animals diverged from each other", so as to measure evolutionary time. "It was a startling idea when it was presented."

Actually, the idea was old and wellestablished. The first molecular comparisons of haemoglobins were made in 1907 and 1909 by E.T. Reichert and A.P. Brown ${ }^{2,3}$. They found, for example, that cats, dogs, a bear and a seal could be placed in four divergent groups on the basis of axial ratio in crystals of their reduced haemoglobins. Their findings were widely quoted in textbooks.

In 1961, V.M. Ingram ${ }^{4}$ published a phylogenetic tree showing the successive separation of myoglobin and alpha, gamma, beta and delta haemoglobins from a common ancestor.

The concept of "molecular disease" was introduced by A.P. Garrod's publication on inborn errors of metabolism in 1908. It was Hardin Jones at the University of California, Berkeley, who first pointed out the dangers of low-level radiation from nuclear testing; indeed, Pauling lists a reference to Jones ${ }^{5}$ in his book ${ }^{6}$.

Thomas H. Jukes

University of California,

Berkeley,

California 94720, USA

1. Rich, A. Nature 371, 285 (1994)

2. Reichert, E.T. \& Brown, A.P. Proc. Soc. exp. Biol. Med. 5. 66-75 (1907).

3. Reichert. E. T. \& Brown, A. P. Monograph, Carnegie Institute of Washington, Washington DC (1909).

4. Ingram, V. M. Nature 189, 704-709 (1961).

5. Jones, H. B. University of California Radiation Laboratory Publication No. 3105 (1955).

6. Pauling, L. How to Live Longer and Feel Better (Freeman, New York, 1986).

\section{Experimenting on the vulnerable}

SIR - A recent issue of Monthly Nature contained an article suggesting male contraception by vasectomy and cryopreservation of sperm for eventual artificial insemination $^{1}$. But the first steps in implementing this otherwise attractive scheme, as proposed by the authors, are that ". . . the military services should begin a large-scale sperm cryopreservation programme".

I think that we should remember that, as agreed in international guidelines on human experimentation ${ }^{2}$, military personnel belong to a vulnerable group. Such people (prisoners, medical students, children, those with mental disorders) should not be used for medical research because of their restricted freedom to make independent choices.

Despite the authors' view ${ }^{1}$ that army personnel have a higher risk of early death and may therefore be interested in preservation of sperm, I do not think that this is a good argument for approving experimentation on soldiers and on prisoners. Vasily Vlassov

(Colonel of Medical Corps)

Committee on Biomedical Ethics,

Saratov Medical University,

POBox 1528 ,

Saratov 110601

Russia

1. Djerassi, C. \& Leibo, S. P. Nature 370, 11-12 (1994).

2. International Ethical Guidelines for Biomedical Research involving Human Subjects (CIOMS, Geneva, 1993). 